\title{
New Treatments for Diabetic Chronic Kidney Disease
}

\section{Richard J Maclsaac ${ }^{1,2,5 *}$, Elif I Ekinci ${ }^{3}$, Darren J Kelly4,5 and George Jerums ${ }^{3,5}$}

${ }^{1}$ Department of Endocrinology \& Diabetes, St Vincent's Hospital Melbourne, Australia

${ }^{2}$ St Vincent's Institute of Medical Research Melbourne, Australia

${ }^{3}$ Endocrine Centre \& Department of Medicine, Austin Health, Australia

${ }^{4}$ Depatment of Medicine, St Vincent's Hospital Melbourne, Australia

${ }^{5}$ University of Melbourne, Victoria, Australia

\begin{abstract}
Despite the availability of current therapies that target hyperglycemia, hypertension, dyslipidemia and blockade of the renin-angiotensin-aldosterone (RAA) system, many people with diabetic chronic kidney disease (CKD) still progress to end stage renal disease (ESRD). Hence, new therapies to slow the progression of this important diabetic complication are urgently needed. Disappointingly many promising interventions for diabetic CKD have not coming to fruition when tested in large clinical trials. A recent clinical trial has shown that estimated GFR increases with bardoxolone. However, this finding awaits confirmation that it reflects changes in true GFR and translation into a reduction in clinical events. Here we discuss studies that have evaluated the effects of novel approaches to inhibiting the pathways involved in the pathogenesis of diabetic CKD.
\end{abstract}

\section{Introduction}

It has been recognised for some time that the incidence of type 2 diabetes is increasing worldwide as a result of the combination of obesity, urbanisation and an ageing population. The public health impact of this phenomenon is enormous and will mainly be driven by the concurrent increase in the prevalence of diabetes related complications. This situation is exemplified by the rapid increase in chronic kidney disease (CKD) and end-stage renal disease (ESRD) in people with diabetes. Indeed, diabetes is now the leading cause of ESRD in the world [1]

CKD in people with diabetes has traditionally been referred to as "diabetic nephropathy". Diabetic nephropathy is usually defined as persistent clinically detectable proteinuria (macroalbuminuria) that is associated with an elevation in blood pressure and a decline in GFR, and has been reported to occur in 25 to $40 \%$ of people with either type 1 or type 2 diabetes [2]. Historically, the earliest clinical manifestation of diabetic CKD has been the detection of persistent microalbuminuria [3]. The finding of microalbuminuria represents a categorical increase in urinary albumin excretion rate (AER) and has traditionally been equated with incipient nephropathy. Early studies suggested that GFR only starts to decrease when AER reaches the macroalbuminuric range [4]. This conventional paradigm of kidney disease in people with diabetes has been challenged recently. Most people with diabetes that are destined to develop CKD follow a traditional "albuminuric pathway". However, it is becoming increasingly recognised that some people with diabetes develop CKD that is not associated with an increase in AER [5]. Furthermore, not all patients with diabetes who develop CKD display the classic glomerular morphological features of diabetic nephropathy [6].

Until recently, diabetic CKD was classified according to albuminuria categories (Table 1). A more contemporary approach involves the integration of albuminuria categories with stages of GFR (Table 2) as promoted by the recent Kidney Disease: Improving Global Outcomes

\begin{tabular}{|l|c|c|c|c|}
\hline & \multicolumn{2}{|c|}{ AER } & \multicolumn{2}{c|}{$\begin{array}{c}\text { ACR } \\
\text { (mg per mmol or mg per g) }\end{array}$} \\
\hline & $\mu \mathrm{g} / \mathrm{min}$ & $\mathrm{mg} /$ day & Females & Males \\
\hline Normoalbuminuria & $<20$ & $<30$ & $<3.5 /<35$ & $<2.5 /<25$ \\
\hline Microalbuminuria & $20-200$ & $30-300$ & $3.5-35 / 35-350$ & $2.5-25 / 25-250$ \\
\hline Macroalbuminuria & $>200$ & $>300$ & $>35 />350$ & $>25 />250$ \\
\hline
\end{tabular}

Table 1: Classification of albuminuria for people with diabetes (AER: Albumin Excretion Rate: ACR: Albumin to Creatinine ratio).

\begin{tabular}{|c|c|c|c|c|c|c|c|}
\hline \multirow{2}{*}{\multicolumn{3}{|c|}{$\begin{array}{l}\text { CKD as proposed } \\
\text { by KDIGO Controversies } \\
\text { Conference Report } 2012\end{array}$}} & \multicolumn{5}{|c|}{$\begin{array}{l}\text { Albuminuria stages, description and } \\
\text { range ( } \mathrm{mg} / \mathrm{g} \text { or } \mathrm{mg} / \mathrm{mmol})\end{array}$} \\
\hline & & & \multicolumn{2}{|c|}{ A1 } & \multirow{2}{*}{$\begin{array}{r}\text { A2 } \\
\text { high }\end{array}$} & \multicolumn{2}{|c|}{ A3 } \\
\hline \multirow{2}{*}{\multicolumn{3}{|c|}{$\begin{array}{l}\text { GFR Stages description and } \\
\text { range }\left(\mathrm{ml} / \mathrm{min} \text { per } 1.73 \mathrm{~m}^{2}\right)\end{array}$}} & \multicolumn{2}{|c|}{$\begin{array}{l}\text { Optimal and } \\
\text { high normal }\end{array}$} & & \multicolumn{2}{|c|}{$\begin{array}{l}\text { Very high and } \\
\text { nephrotic }\end{array}$} \\
\hline & & & $\begin{array}{l}<10 \\
<1\end{array}$ & $\begin{array}{l}10-29 \\
1-2.9\end{array}$ & $\begin{array}{l}30-299 \\
3-30\end{array}$ & $\begin{array}{l}300-1999 \\
30-199\end{array}$ & $\begin{array}{l}>2000 \\
>200\end{array}$ \\
\hline \multirow{2}{*}{ G1 } & \multirow{2}{*}{$\begin{array}{l}\text { High and } \\
\text { Optimal }\end{array}$} & $>105$ & & & & & \\
\hline & & $90-104$ & & & & & \\
\hline \multirow{2}{*}{ G2 } & \multirow{2}{*}{ Mild } & $75-89$ & & & & & \\
\hline & & $60-74$ & & & & & \\
\hline G3a & Mild-Moderate & $45-59$ & & & & & \\
\hline G3b & Moderate & $30-44$ & & & & & \\
\hline G4 & Severe & $15-29$ & & & & & \\
\hline G5 & Kidney Failure & $<15$ & & & & & \\
\hline
\end{tabular}

Table 2: The proposed classification of chronic kidney disease (CKD) incorporating albuminuria category (Albumin to Creatinine ratio) and estimated glomerular filtration rate GFR (eGFR) stage as proposed in the Kidney Disease: Improving Global Outcomes (KDIGO) Controversies Conference Report 2012 [7].

(KDIGO) report [7]. People with diabetes and CKD are not only at risk of a progressive decline in renal function but also have an increased risk for developing cardiovascular (CV) disease [8]. Integrating albuminuria and GFR therefore helps to improve the stratification of patients in terms of their risk for progressive renal dysfunction and for the development of CV disease. It also recognises the continuous relationship between albuminuria and adverse renal and CV disease outcomes and the heightened CV disease risk that that occurs when estimated GFR is less than $45 \mathrm{ml} / \mathrm{min} / 1.73 \mathrm{~m}^{2}$.

*Corresponding author: Richard $\mathrm{J}$ Maclsaac, Director, Department of Endocrinology \& Diabetes, St Vincent's Health, Melbourne \& Professorial Fellow, University of Melbourne, 4th Floor, Daly Wing, 35 Victoria Parade, PO Box 2900 Fitzroy, Victoria 3065, Australia, Tel: 6139288 3569; Fax: 6139288 3590; E-mail: Richard.Maclsaac@svhm.org.au

Received February 06, 2012; Accepted March 27, 2012; Published March 29 2012

Citation: Maclsaac RJ, Ekinci El, Kelly DJ, Jerums G (2012) New Treatments for Diabetic Chronic Kidney Disease. J Nephrol Therapeutic S2. doi:10.4172/21610959.S2-006

Copyright: (c) 2012 Maclsaac RJ, et al. This is an open-access article distributed under the terms of the Creative Commons Attribution License, which permits unrestricted use, distribution, and reproduction in any medium, provided the original author and source are credited. 
The pathophysiology of diabetic CKD involves the activation of metabolic, inflammatory and haemodynamic pathways [9]. Metabolic pathways are mainly driven by chronic hyperglycaemia that results in increased protein kinase C (PKC) activity, abnormalities in polyol metabolism, increased secretion of profibrotic cytokines such as transforming growth factor- $\beta$ (TGF- $\beta$ ) and connective tissue growth factor (CTGF), non enzymatic glycosylation leading to the glycation of glomerular and tubular proteins and the production of advanced glycation end products (AGEs). The resultant generation of reactive oxygen species (ROS) and an inflammatory process plays a pivotal role in the development of diabetic CKD.

The hemodynamic pathways promoting the development of diabetic CKD result in systemic and intra-glomerular hypertension. They are driven by the activation of vasoactive systems such as the reninangiotensin-aldosterone (RAA) and endothelin systems. It should be appreciated that the above metabolic, inflammatory and haemodynamic pathways can influence the other. For example, activation of the RAA system promotes endothelial dysfunction, inflammation and the expression of TGF- $\beta$ and CTGF. The final common manifestation of the above pathways is usually the accumulation of excess connective tissue that leads to fibrosis or scarring of the kidney.

Given the exaggerated risk for a progressive decline in GFR and the development of $\mathrm{CV}$ disease in people with $\mathrm{CKD}$ and diabetes, the early identification of these people and the subsequent initiation of renal and CV protective treatments are of the utmost importance. In general, the finding of elevated levels of urinary albumin or a GFR $<60 \mathrm{ml} / \mathrm{min} / 1.73 \mathrm{~m}^{2}$ should provoke an intensified modification of the common risk factors for kidney and cardiovascular disease, i.e. hyperglycemia, hypertension, dyslipidemia and smoking, and the initiation of interventions aimed at RAA system blockade.

Despite the availability of current therapies that target hyperglycemia, hypertension, dyslipidemia and blockade of the RAA system, many people with diabetic CKD still progress to ESRD. Indeed, a long term study from the Joslin Clinic has shown that the incidence of ESRD for patients with type 1 diabetes and macroalbuminuria has not changed over three decades, despite the increased use of angiotensin converting enzyme (ACE) inhibitors and improved lipid and blood pressure parameters [10]. In contrast, type 2 diabetes-related ESRD incidence rates have been reported to decline [1]. Despite this, the absolute number of new cases continues to increase. Hence, new therapies to slow down the progression of this important diabetic complication are urgently needed. Here we discuss studies that have evaluated the effects of novel approaches to inhibiting the pathways involved in the pathogenesis of diabetic CKD.

\section{Novel Approaches to Blocking the Renin-Angiotensin- Aldosterone System}

The potential sites for inhibiting the RAA system are shown in Figure 1. Inhibiting the RAA system by using ACE inhibitors and angiotensin receptor blockers (ARBs) is a proven strategy to slow the rate of CKD progression in diabetes [11]. However, it has been recognised for some time that the use of agents to block the RAA system is only partially effective as they interfere with negative feedback mechanisms resulting in a reactive increase in renin activity. As tissues contain ACE-independent pathways for converting angiotensin I to angiotensin II, an "escape" phenomenon can occur [12].

Dual blockade of the RAA system with an ACE inhibitor and ARB in subjects with diabetes has been demonstrated to be more effective in reducing blood pressure and decreasing albuminuria than either agent

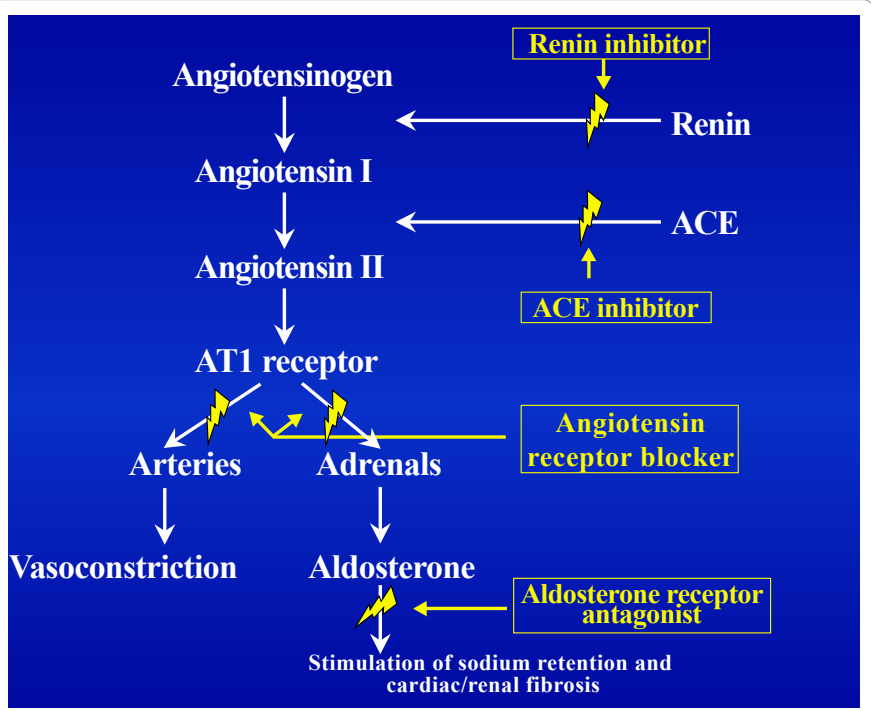

Figure 1: Potential sites for blocking the renin-angiotensin-aldosterone (RAA) system (AT1- angtiotensin type 1 receptor).

as monotherapy [13]. Despite this, the ONgoing Telmisartan Alone and in combination with Ramipril Global Endpoint Trial (ONTARGET) involving high risk vascular patients, the majority not having diabetes or renal dysfunction, showed that combination therapy was not superior to ACE inhibition alone in regard to $\mathrm{CV}$ and renal outcomes. Indeed, combination therapy was associated with an increased risk of adverse renal outcomes which was mainly accounted for by the need for acute dialysis [14]. The combination of an ACE inhibitor and ARB is therefore generally not advised. However, the effectiveness of combining an ACE inhibitor and an ARB still remains to be rigorously tested in the setting of established $\mathrm{DN}$ and this approach is currently being evaluated in a clinical trial (VA NEPHRON-D) [15].

One novel potentially renoprotective approach involving RAA system blockade is to directly inhibit the action of renin and hence the conversion of angiotensinogen to angiotensin I. In the Aliskiren in the Evaluation of Proteinuria in Diabetes (AVOID) clinical trial, the oral direct-renin inhibitor, aliskiren, reduced albuminuria in overtly proteinuric subjects with type 2 diabetes who were already receiving maximal recommended doses of an ARB [16]. There was a small reduction in $\mathrm{BP}$ with aliskiren $(2 / 1 \mathrm{~mm} \mathrm{Hg})$, but the authors of the study concluded that the beneficial effects on albuminuria were independent of BP changes. Furthermore, adverse events, including hyperkalaemia were similar in subjects taking an ACE inhibitor who were then randomised to aliskiren or placebo therapy. However, it should be noted that subjects in the AVOID study, although having overt proteinuria still had relatively well preserved renal function with a mean estimated GFR (eGFR) of $67 \mathrm{ml} / \mathrm{min} / 1.73 \mathrm{~m}^{2}$ at baseline.

Unexpectedly, this potentially promising intervention has not been shown to improve clinical outcomes, resulting in the premature termination of the Aliskiren Trial in Type 2 Diabetes Using CardioRenal Endpoints (ALTITUDE) study. This trial aimed to test the effectiveness of aliskiren in preventing renal and cardiac events in participants with type 2 diabetes and CKD already receiving ACE inhibition or ARB therapy who were then subsequently randomised to aliskiren or placebo [17]. Of interest, the eGFR of subjects enrolled in the ALTITUDE study ranged between $\geq 30$ to $<60 \mathrm{ml} / \mathrm{min} / 1.73 \mathrm{~m}^{2}$. The Data Monitoring Committee of the trial recommended its termination because of an increased risk for non-fatal stroke, renal complications, 
hyperkalaemia and hypotension in participants taking aliskiren for 1824 months [18].

The use of aldosterone receptor antagonists has been investigated as a means of overcoming the escape phenomenon discussed above. Aldosterone receptor antagonism with spironolactone reduces albuminuria with or without concurrent blood pressure reduction in subjects with diabetes and nephropathy $[19,20]$. Current evidence suggests no advantage of triple blockade (spironoloctone, ACEi and ARB) over dual blockade on proteinuria. In any event, hormonal and metabolic side-effects especially kyperkalaemia, limit the applicability of the approach of adding an aldosterone receptor blocker to an ACEi or ARB to some extent. Furthermore, given the results of the ON TARGET and ALTITUDE studies it is very doubtful that the risk versus benefit of combining aldosterone receptor blockade with an ACE inhibitor or an ARB in subjects with diabetic nephropathy will ever be assessed in a large trial examining clinical outcomes.

\section{Other Vasoactive Substances}

Endothelin-1 has been implicated as an important mediator of progressive renal injury. In diabetic rats with diabetic nephropathy, the endothelial type A receptor antagonist, avosentan, when combined with ACE inhibition, significantly reduced proteinuria and reversed the glomerular and tubulointerstitial changes normally seen in this model [21]. Furthermore, in a randomized, placebo-controlled clinical trial involving 286 subjects with type 1 or 2 diabetes receiving standard ACE inhibition or ARB therapy, avosentan reduced the albumin to creatinine ratio (ACR) compared with placebo [22]. Creatinine clearance and BP were unchanged after 12 weeks of treatment. The main adverse event was peripheral oedema, occurring in $12 \%$. Hepatotoxicity has been implicated a potential side effect of avosentan, but significant increases in liver enzymes did not occur in this trial. Once again no studies assessing clinical outcomes of avosentan therapy in combination with ACE inhibition or an ARB have been performed. In summary, endothelin type A antagonists reduce albuminuria but currently appear to have a significant side-effect profile that may limit their use in clinical practice [23].

\section{Targeting Glycation}

The role of abnormal indices of advanced glycation in the pathogenesis of experimental diabetic CKD has been highlighted recently. It has been proposed that activation of the receptor for advanced glycation endproducts (RAGE) via a decrease in angiotensin II type 2 receptors plays a key role in promoting the development and progression of diabetic CKD [24]. Targeting glycation has also been proposed as a novel approach to preventing the progression of diabetic CKD.

Aminoguanidine, an inhibitor of the formation of advanced glycation end-products (AGEs), has been shown to reduce albuminuria and morphological renal changes in experimental diabetes [25]. However, two large clinical studies of aminoguanidine in patients with type 1 (ACTION 1 ) and type 2 (ACTION 2 ) diabetes were terminated due to safety concerns and apparent lack of efficacy [26,27].

Pyridoxamine is another inhibitor of AGE formation. It has been shown to reduce the toxic effects of reactive oxygen species and to scavenge reactive carbonyl compounds. There is some clinical trial evidence to suggest that pyridoxamine lowers serum creatinine, as well as decreasing urinary TGF- $\beta$ and AGEs but these effects have yet to be translated into any consistent effect on renal outcomes [28]. Indeed, a recent double-blind, randomised, placebo-controlled trial in macroalbuminuric subjects with type 2 diabetes showed that pyridoxamine treatment failed to decrease urinary protein excretion or progression of serum creatinine over 1 year [29]. In the subgroup of participants with the lowest tertile of serum creatinine at baseline < $164 \mu \mathrm{mol} / \mathrm{L}(1.85 \mathrm{mg} / \mathrm{dl})$, treatment with pyridoxamine was associated with a lower average increase in serum creatinine at 52 weeks but this was not translated into a significant attenuation in the decline in eGFR over this time period. Whether pyridoxamine helps to preserve renal function in a subgroup of patients with diabetic CKD needs to be rigorously tested in a clinical study extending over a number of years.

Treatment with ALT-711 (Alagebrium), a breaker of AGE crosslinks, results in a reduction in albuminuria, blood pressure and an amelioration of structural damage to the kidney in experimental diabetes [30]. The usefulness of this compound in inhibiting the progression of DN in the clinical setting still remains unclear, in part because of the premature cancellation of a study of alagebrium in subjects with type 1 diabetes and microalbuminuria due to financial constraints [31].

\section{Vitamins}

Recently, paricalcitol, a vitamin D receptor activator, has been shown to reduce albuminuria in subjects with type 2 diabetes and DN without an increased incidence of hypercalcaemia or other serious adverse events [32]. Whether vitamin $\mathrm{D}$ receptor activation results in preservation of GFR has yet to be tested in clinical trials. The potential benefits of vitamin D are most likely the result of an interaction with multiple pathways that promote the development and progression of renal dysfunction, including the RAA system [33]. In contrast, other vitamins, such as vitamin $B$ complexes, have been shown to have no effect on proteinuria in subjects with $\mathrm{DN}$ and to cause an unexpected decline in GFR as measured by a radionucleotide technique [34].

High dose thiamine and benfotiamine have both been found to retard the development of microalbuminuria in experimental diabetes via decreased activation of protein kinase $\mathrm{C}$ and decreased protein glycation and oxidative stress [35]. In a pilot study involving thiamine deficient subjects in Pakistan with type 2 diabetes and microalbuminuria, thiamine replacement resulted in a significant reduction in ACR [36]. In contrast, benfotiamine does not appear to have any effect on urinary albumin excretion in subjects with type 2 diabetes [37].

\section{Anti-Fibrotic Agents}

Other potential treatment strategies that target the fibrosis and scarring observed in diabetic CKD also deserve mention. Pirfenidone is an anti-fibrotic drug approved for idiopathic pulmonary fibrosis, that has also been shown to provide benefit in patients with diabetic nephropathy. In a double blind, randomised placebo controlled study of 77 patients, pirfenidone, albeit at high doses (1200-mg/d), increased mean eGFR in the pirfenidone group $(+3.3+/-8.5 \mathrm{ml} /$ $\left.\mathrm{min} / 1.73 \mathrm{~m}^{2}\right)$ compared to a decrease in the placebo group $(-2.2+/-4.8$ $\mathrm{ml} / \mathrm{min} / 1.73 \mathrm{~m}^{2}$ ) after 52 weeks of treatment. However, pirfenidone did not reduce albuminuria [38].

Tranilast, an approved anti-allergic drug with inhibitory effects on profibrotic growth factors and extracellular matrix accumulation [39] has also been tested in a small clinical trial. The data suggested that in addition to standard treatment with an ACE inhibitor or an $\mathrm{ARB}$, tranilast can decrease albuminuria in subjects with type 2 diabetes and raised ACR values [40]. The treatment was generally well tolerated, however in large clinical trials such as the Prevention of 
REStenosis with Tranilast and its Outcomes (PRESTO) trial, tranilast was associated with adverse effects [41]. A re-engineered analogue of tranilast (FTo11) exhibits 2-5 times more potency than tranilast [42] and is about to begin early stage clinical trials for its anti-fibrotic potential in patients with $\mathrm{DN}$.

Other interesting anti-fibrotic compounds in the early stages of preclinical to clinical development for fibrosis are AM152, an orally available lysophosphatidic acid 1 (LPA1) receptor antagonist which has completed Phase I clinical studies, and Galectin-3 antagonists, which are central in macrophage and fibroblast differentiation and may also protect against AGE-induced renal injury. This approach of using specific antifibrotic agents to slow the progression of diabetic CKD awaits further evaluation in a large clinical trial.

\section{Targeting Inflammation and Oxidative Stress with Bardoxolone}

Bardoxolone methyl is an oral activator of nuclear factor erythroidrelated factor 2 (Nrf2). Activation of this transcription factor results in the upregulation of a variety of antioxidant, detoxification and antiinflammatory responses [43]. In experimental diabetes, activation of Nrf2 has been shown to result in renoprotective effects [44]. In a recent clinical trial, 227 subjects with type 2 diabetes and CKD stages 3 to 4 (eGFR 20 to $45 \mathrm{ml} / \mathrm{min} / 1.73 \mathrm{~m}^{2}$ ) were randomised to receive bardoxolone ( 25 to $150 \mathrm{mg}$ per day) or placebo in addition to RAA blocking therapy [45]. The primary end point of the study was the change in eGFR from baseline at 24 weeks.

Bardoxolone treatment increased eGFR by $8.2 \pm 1.5$ ( $25 \mathrm{mg}$ dose $)$, $11.4 \pm 1.5$ (50 mg dose) and $10.4 \pm 1.5$ (75 $\mathrm{mg} \mathrm{dose}) \mathrm{ml} / \mathrm{min} / 1.73 \mathrm{~m}^{2}$, all $\mathrm{p}<0.001$ compared with placebo. An increase in eGFR was even seen after 4 weeks of starting bardoxalone therapy and was sustained for 52 weeks (Figure 2). Four weeks after the last dose of bardoxolone was administered, eGFR levels were still above baseline values but these values were only $25 \%$ of that seen during active treatment.

During the study no correlation was seen between changes in eGFR and systemic blood pressure and no change in mean systemic blood pressure levels was seen in any of the treatment groups. The rapid increase in estimated GFR seen in the study suggests that bardoxolone may have some reversible hemodynamic effect within the kidney. As only estimated GFR was used in this study it remains possible that the changes in GFR reported in the study was due an effect of bardoxolone on creatinine production or the handling of creatinine by the kidney. It is therefore necessary to confirm that the increase in estimated GFR reflects changes in measured GFR as opposed to an indirect effect of bardoxolone on creatinine metabolism.

The attenuated but sustained increase in eGFR seen after discontinuation of bardoxolone also suggests that bardoxolone possibly inhibits the inflammation and oxidative stress pathways that are known to promote the development of diabetic CKD. The main side-effect of bardoxolone therapy was muscle spasms which were reported by 40 to $60 \%$ of participants in the study. An increased prevalence of muscle spasms was reported with the higher doses of the drug, however they were reported to generally resolve without discontinuation of the drug.

Interestingly, the increase in eGFR seen with bardoxolone occurred independently of changes in albumin excretion. Indeed, the urinary ACR level increased with active treatment and changes in ACR and eGFR were positively correlated at 52 weeks. It was suggested by the authors of the study that this discordance between eGFR and ACR may

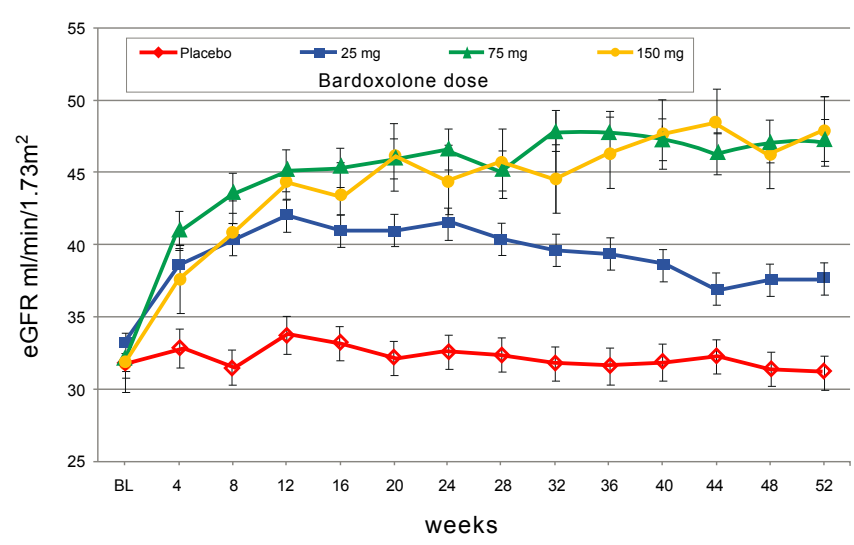

Figure 2: Effects of different doses of bardoxolone on estimated GFR (eGFR) 52 weeks in 227 subjects with type 2 diabetes and chronic kidney disease (CKD). Modified with permission from reference 45.

possibly be related to increased glomerular filtration and decreased tubular reabsorption of albumin due to increased rate of tubular transit.

The Bardoxolone Methyl Evaluation in patients with Chronic Kidney Disease and Type 2 Diabetes-The Occurrence of Renal Events (BEACON) plans to randomise 1600 participants with stage $4 \mathrm{CKD}$ and type 2 diabetes to placebo or bardoxolone. Intersestingly this trial has commenced without confirmation that the increase in eGFR seen with Bardoxolone reflects changes in true GFR. The trail is expected to run for 3 years with the primary end point being progression to ESRD or cardiovascular death [46]. It is hoped that BEACON will show that the increase in eGFR observed in the above trial will be translated into a reduction in clinical renal and $\mathrm{CV}$ disease events.

\section{Lipid Lowering Agents}

A substudy from the Collaborative Atorvastatin Diabetes Study (CARDS) showed that over approximately 4 years, atorvastatin ameliorated the expected decline in eGFR in patients with elevated levels of urinary albumin (net improvement of $0.38 \mathrm{ml} / \mathrm{min} / 1.73 \mathrm{~m}^{2}$ per year, $p=0.03$ ) compared with placebo treatment [47]. A recent observational study has also shown that the use of statins was associated with a reduced risk ( $68 \%$ risk reduction) of developing renal dysfunction (defined as an eGFR $<60 \mathrm{ml} / \mathrm{min} / 1.73 \mathrm{~m}^{2}$ or first hospitalisation with renal disease) in 5264 subjects with type 2 diabetes (approximatedy $25 \%$ taking statins) followed for 5 years [48]. Recent preliminary data from a randomised controlled trial, the Prospective Evaluation of Proteinuria and Renal Function in Diabetic Patients With Progressive Renal Disease (PLANET I), which has only been published in abstract form, has suggested that not all statins have the same renal effects [49]. PLANET I involved 325 patients with type 1 or 2 diabetes who had proteinuria with an eGFR $>40 \mathrm{~mL} / \mathrm{min} / 1.73 \mathrm{~m}^{2}$ and who were already on ACE inhibitors or ARBs. Patients were randomized to receive rosuvastatin ( $10 \mathrm{or} 40 \mathrm{mg} /$ day) or atorvastatin $80 \mathrm{mg} /$ day. The primary end point of the study was the change in urinary protein/creatinine ratio from baseline to 52 weeks. Atorvastatin therapy significantly reduced the proteinuria by approximately $15 \%$ whereas rosuvastatin therapy (both 10 and $40 \mathrm{mg}$ ) had no significant effect on proteinuria. In terms of changes in eGFR, patients receiving atorvastatin lost about 1 to $2 \mathrm{~mL} / \mathrm{min} / 1.73 \mathrm{~m}^{2}$ over 52 weeks whereas those on rosuvastatin $10 \mathrm{mg} /$ day lost about $4 \mathrm{~mL} / \mathrm{min}$ per $1.73 \mathrm{~m}^{2}$ and those receiving rosuvastatin $40 \mathrm{mg} /$ day approximately $8 \mathrm{~mL} / \mathrm{min} / 1.73 \mathrm{~m}^{2}$. 
The above results need to be interpreted with caution and await peer reviewed publication. Furthermore, one of the limitations of the above study and for most other studies involving lipid lowering medications, including fenofibrate (as discussed below), is that measurement of GFR has mainly been based on creatinine derived estimates of GFR. In a situation analogous to the bardoxolone study discussed in the last section, creatinine based estimates of GFR can be influenced by other non GFR related factors factors such as creatinine production and secretion which could be affected by lipid lowering medications without altering true GFR.

It is important to emphasize that intensive treatment of dyslipidaemia in people with diabetes should be considered not only to possibly ameliorate renal injury but also to avoid CV complications. A substudy of the Treating to New Targets (TNT) study showed that atorvastatin $80 \mathrm{mg}$ compared with atorvastatin $10 \mathrm{mg}$ reduced the relative risk of major CV events in patients with an eGFR $<60 \mathrm{ml} /$ $\mathrm{min} / 1.73 \mathrm{~m}^{2}$ and coronary heart disease (approximately 15\% with diabetes) by $32 \%(\mathrm{p}=0003)$ compared with $15 \%(\mathrm{p}=0.049)$ in patients with eGFR levels $\geq 60 \mathrm{ml} / \mathrm{min} / 1.73 \mathrm{~m}^{2}$ [50]. The recent Study of Heart And Renal Protection (SHARP) also showed that in patients with CKD (approximately 25\% having diabetes) the combination of simvastatin and ezetimibe compared with placebo decreased total CV events [51]. However, to date there is no evidence to suggest that statins reduce $\mathrm{CV}$ events in people who have already developed ESRD [52].

In the Fenofibrate Intervention and Event Lowering in Diabetes (FIELD) and ACCORD studies, the use of fenofibrate was shown to reduce albuminuia [53]. A further analysis of the FIELD study has shown that fenofibrate causes an acute but sustained plasma creatinine increase which may not reflect changes in true GFR [54]. This suggestion has yet to be tested by the direct measurement of GFR.

At the end of the interventional phase of the FIELD study plasma creatinine levels were re-measured eight weeks after treatment cessation. After this washout period, eGFR had fallen less from baseline for patients treated with fenofibrate $\left(1.9 \mathrm{ml} / \mathrm{min} / 1.73 \mathrm{~m}^{2}\right)$ than on placebo treatment $\left(6.9 \mathrm{ml} / \mathrm{min} / 1.73 \mathrm{~m}^{2}\right)$, sparing $5.0 \mathrm{ml} / \mathrm{mim} / 1.73 \mathrm{~m}^{2}$ of GFR ( $p<0.001)$. Greater preservation of eGFR with fenofibrate was observed in patients with baseline hypertriglycerideaemia alone or when combined with a low HDL-cholesterol level. Furthermore, fenofibrate reduced urinary ACR by $24 \%$ versus $11 \%$ with placebo treatment $(\mathrm{p}<0.001)$. There was $14 \%$ less progression and $18 \%$ more regression of albuminuria in fenofibrate compared with placebo treated patients $(\mathrm{p}<0.001)$. However, ESRD event frequency was similar for fenofibrate and placebo treated patients $(n=21$ vs $26, p$ $=0.48$ ). The FIELD investigators interpreted these findings to mean that use of fenofibrate is associated with a reduction in albuminuria and a slowing in eGFR decline despite initial and reversible increases in plasma creatinine.

Both the FIELD and the ACCORD- lipid studies have also shown that fenofibrate slows the progression of diabetic retinopathy [55]. The mechanisms by which fenofibrate exerts this beneficial effect on albuminuria and potentially GFR are still yet to be fully elucidated but generally appear to be independent of effects on lipid parameters and most likely involve inhibition of inflammatory pathways and cytokines such as vascular endothelial growth factor.

\section{Other Novel Approaches}

In experimental studies, the use of an inhibitor of the $\beta$ isoform of protein kinase $\mathrm{C}$ (ruboxistaurin), has resulted in a decrease in albuminuria, normalisation of hyperfiltration, a reduction in TGF- $\beta$ and a reduction in extracellular matrix accumulation in the kidney of diabetic rodents [56,57]. Unfortunately clinical studies of this compound have not shown clear renal benefits [58].

One proposed mechanism for the development of albuminuria in $\mathrm{DN}$ is depletion of glycosaminoglycans in the glomerular basement membrane (GBM). In experimental and small clinical studies, sulodexide, a compound containing a mixture of glycosaminoglycans, has been shown to reduce albuminuria, possibly through restoring glomerular glycoproteins or by restoring anionic heparin sulphate charge on the GBM. Furthermore, small, short-term clinical trials have suggested that sulodexide can reduce albuminuria $[59,60]$. However, in a large double blind, randomised control (SUN-Micro) trial involving 1000 patients with type 2 diabetes and microalbuminuria who were already receiving maximal doses of ACE inhibitors or ARBs, sulodexide failed to reduce albuminuria [61].

A further trial in macroalbuminuric subjects with type 2 diabetes also failed to demonstrate any renoprotective effects of sulodexide [62]. In this trial the endpoint was a composite of doubling of serum creatinine, development of ESRD or serum creatinine $>530 \mu \mathrm{mol} / \mathrm{L}$ $(6.0 \mathrm{mg} / \mathrm{dL})$. There was also no change in ACR with sulodexide compared with placebo.

Pathways pivotal to the development of DN possibly are activated by the acetylation status of histone proteins. Furthermore, inhibiting histone deacetylase (HDAC) is emerging as a potentially useful approach to attenuating renal injury in diabetes. Daily subcutaneous injections of the HDAC inhibitor trichostatin A have been shown to reduce proteinuria in experimental diabetes [63]. More recently, oral treatment with another HDAC inhibitor, vorinostat, blunted renal growth and glomerular hypertrophy in diabetic rats [64]. This may be an important finding because one of the early features of diabetic nephropathy is renal enlargement. The effects of vorinostat are hypothesized to be medicated in part by down regulation of epidermal growth factor.

Pentoxifylline, a xanthine derivative, has been demonstrated to have anti-protenuric effects in small clinical trials involving subjects with type 1 and type 2 diabetes [65]. A larger trial, pentoxifylline for reno-protection in diabetic nephropathy (the PREDIAN study) is a randomised, controlled trial that is currently being performed in subjects with type 2 diabetes and stage 3-4 chronic kidney disease [66]. The trial will run for 24 months and will evaluate the effects of pentoxifylline on changes in eGFR.

Serum uric acid (SUA) concentration is emerging as an independent risk factor for the development of diabetic CKD. Treatment with the ARB, losartan has been shown to lower SUA levels in macroalbuminuric patients with type 2 diabetes compared with placebo [67]. Furthermore, the degree of reduction in SUA seen with losartan was subsequently associated with a reduced risk for the renal outcome of a doubling of serum creatinine or the development of ESRD. This effect was independent of other risk factors, including eGFR and albuminuria.

In a trial of 113 patients with an eGFR $<60 \mathrm{ml} / \mathrm{min} / 1.73 \mathrm{~m}^{2}$, approximately $20 \%$ with diabetes, eGFR decreased by $3.3 \pm 1.2 \mathrm{ml} / \mathrm{min}$ $/ 1.73 \mathrm{~m}^{2}$ in the control group and increased by $1.3 \pm \mathrm{ml} / \mathrm{min} / 1.73 \mathrm{~m}^{2}$ in a group treated with allopurinol for 24 months [68]. Furthermore, SUA levels and C-reactive protein levels decreased significantly in 
Citation: Maclsaac RJ, Ekinci El, Kelly DJ, Jerums G (2012) New Treatments for Diabetic Chronic Kidney Disease. J Nephrol Therapeutic S2. doi:10.4172/2161-0959.S2-006

subjects treated with allopurinol. In this small study there were 15/56 $\mathrm{CV}$ events in the control group and 7/57 CV events in the allopurinol group at the end of the follow up period. Although this study suggests a potential positive CV disease benefit of allopurinol, this finding requires confirmation in large prospective trials.

\section{Conclusions}

In conclusion, there has been significant progress in the development of novel treatments for diabetic kidney CKD in recent times despite the potential benefits of promising DN interventions such as aminoguanidine, sulodexide and aliskiren not coming to fruition when tested in large clinical trials. The increase in estimated GFR seen with bardoxolone awaits translation into a reduction in clinical events associated with diabetic CKD. Possibly, even older drugs such as allopurinol may be shown to play an important role in ameliorating the progression of diabetic CKD in future years. However, it should be remembered that in patients at high risk for the development of progressive diabetic $\mathrm{CKD}$, using existing therapies as part of a targetdriven, intensive, multifactorial intervention results in a reduced risk of CV death and progression to ESRD, as shown in the STENO-2 and other studies[69,70].

\section{References}

1. Reutens AT, Atkins RC (2011) Epidemiology of diabetic nephropathy. Contrib Nephrol 170:1-7.

2. Rossing P (2006) Diabetic nephropathy: worldwide epidemic and effects of current treatment on natural history. Curr Diab Rep 6: 479-483.

3. Standards of medical care in diabetes--2009. Diabetes Care 321: 13-61.

4. Mogensen CE (1999) Microalbuminuria, blood pressure and diabetic renal disease: origin and development of ideas. Diabetologia 42: 263-285.

5. Macisaac RJ, Jerums G (2011) Diabetic kidney disease with and without albuminuria. Curr Opin Nephrol Hypertens 20: 246-257.

6. Fioretto P, Mauer M (2007) Histopathology of diabetic nephropathy. Semin Nephrol 27: 195-207.

7. Levey AS, de Jong PE, Coresh J, El Nahas M, Astor BC, et al. (2011)The definition, classification, and prognosis of chronic kidney disease: a KDIGO Controversies Conference report. Kidney Int 80: 17-28.

8. Bakris G, Vassalotti J, Ritz E, Wanner C, Stergiou G, et al. (2010) National Kidney Foundation consensus conference on cardiovascular and kidney diseases and diabetes risk: an integrated therapeutic approach to reduce events. Kidney Int 78: 726-736.

9. Jerums G, Premaratne E, Panagiotopoulos S, Clarke S, Power DA, et al. (2008) New and old markers of progression of diabetic nephropathy. Diabetes Res Clin Pract 1: S30-S37.

10. Rosolowsky ET, Skupien J, Smiles AM, Niewczas M, Roshan B, et al. (2011) Risk for ESRD in type 1 diabetes remains high despite renoprotection. J Am Soc Nephrol 22: 545-553.

11. Strippoli GF, Bonifati C, Craig M, Navaneethan SD, Craig JC (2006) Angiotensin converting enzyme inhibitors and angiotensin II receptor antagonists for preventing the progression of diabetic kidney disease. Cochrane Database Syst Rev CD006257

12. Mooser V, Nussberger J, Juillerat L, Burnier M, Waeber B, et al. (1990) Reactive hyperreninemia is a major determinant of plasma angiotensin II during ACE inhibition. J Cardiovasc Pharmacol 15: 276-282.

13. Jennings DL, Kalus JS, Coleman Cl, Manierski C, Yee J (2007) Combination therapy with an ACE inhibitor and an angiotensin receptor blocker for diabetic nephropathy: a meta-analysis. Diabet Med 24: 486-493.

14. Mann JF, Schmieder RE, McQueen M, Dyal L, Schumacher H, et al. (2008) Renal outcomes with telmisartan, ramipril, or both, in people at high vascular risk (the ONTARGET study): a multicentre, randomised, double-blind, controlled trial. Lancet 372: 547-553.

15. Fried LF, Duckworth W, Zhang JH, O'Connor T, Brophy M, et al. (2009) Design of combination angiotensin receptor blocker and angiotensin-converting enzyme inhibitor for treatment of diabetic nephropathy (VA NEPHRON-D). Clin J Am Soc Nephrol 4: 361-368.

16. Parving HH, Persson F, Lewis JB, Lewis EJ, Hollenberg NK (2008) Aliskiren combined with losartan in type 2 diabetes and nephropathy. N Engl J Med 358 2433-2446.

17. Parving HH, Brenner BM, McMurray JJ, de Zeeuw D, Haffner SM, et al. (2009) Aliskiren Trial in Type 2 Diabetes Using Cardio-Renal Endpoints (ALTITUDE): rationale and study design. Nephrol Dial Transplant 24: 1663-1671.

18. www.novartis.com/newsroon/media-release/en/2011 [cited 2011 23.12.2011]

19. Rachmani R, Slavachevsky I, Amit M, Levi Z, Kedar Y, et al. (2004) The effect of spironolactone, cilazapril and their combination on albuminuria in patients with hypertension and diabetic nephropathy is independent of blood pressure reduction: a randomized controlled study. Diabet Med 21: 471-475.

20. Rossing K, Schjoedt KJ, Smidt UM, Boomsma F, Parving HH (2005) Beneficial effects of adding spironolactone to recommended antihypertensive treatment in diabetic nephropathy: a randomized, double-masked, cross-over study. Diabetes Care 28: 2106-2112.

21. Watson AM, Li J, Schumacher C, de Gasparo M, Feng B, et al. (2010) The endothelin receptor antagonist avosentan ameliorates nephropathy and atherosclerosis in diabetic apolipoprotein $\mathrm{E}$ knockout mice. Diabetologia 53:192-203.

22. Wenzel RR, Littke T, Kuranoff S, Jurgens C, Bruck H, et al. (2009) Avosentan reduces albumin excretion in diabetics with macroalbuminuria. J Am Soc Nephrol 20: 655-664.

23. Jandeleit-Dahm KA, Watson AM (2012) The endothelin system and endothelin receptor antagonists. Curr Opin Nephrol Hypertens 21: 66-71.

24. Sourris KC, Morley AL, Koitka A, Samuel P, Coughlan MT, et al. (2010) Receptor for AGEs (RAGE) blockade may exert its renoprotective effects in patients with diabetic nephropathy via induction of the angiotensin II type 2 (AT2) receptor. Diabetologia 53: 2442-2451.

25. Soulis-Liparota T, Cooper M, Papazoglou D, Clarke B, Jerums G (1991) Retardation by aminoguanidine of development of albuminuria, mesangial expansion, and tissue fluorescence in streptozocin-induced diabetic rat. Diabetes 40: 1328-1334.

26. Bolton WK, Cattran DC, Williams ME, Adler SG, Appel GB, et al. (2004) Randomized trial of an inhibitor of formation of advanced glycation end products in diabetic nephropathy. Am J Nephrol 24: 32-40.

27. Freedman BI, Wuerth JP, Cartwright K, Bain RP, Dippe S, et al. (1999) Design and baseline characteristics for the aminoguanidine Clinical Trial in Overt Type 2 Diabetic Nephropathy (ACTION II). Control Clin Trials 20: 493-510.

28. Williams ME, Bolton WK, Khalifah RG, Degenhardt TP, Schotzinger RJ, et al (2007) Effects of pyridoxamine in combined phase 2 studies of patients with type 1 and type 2 diabetes and overt nephropathy. Am J Nephrol 27: 605-614.

29. Lewis EJ, Greene T, Spitalewiz S, Blumenthal S, Berl T, et al. (2012) Pyridorin in Type 2 Diabetic Nephropathy. J Am Soc Nephrol 23: 131-136.

30. Park J, Kwon MK, Huh JY, Choi WJ, Jeong LS, et al. (2011) Renoprotective antioxidant effect of alagebrium in experimental diabetes. Nephrol Dial Transplant 26: 3474-3784.

31. Synvista Treapeutics announces termination of clinical trials of alegebrium [cited 2012 20.01.2012]

32. de Zeeuw D, Agarwal R, Amdahl M, Audhya P, Coyne D, et al. (2010) Selective vitamin $D$ receptor activation with paricalcitol for reduction of albuminuria in patients with type 2 diabetes (VITAL study): a randomised controlled trial. Lancet 376: 1543-1551.

33. Thomas MC, Cooper ME (2010) Into the light? Diabetic nephropathy and vitamin D. Lancet 376: 1521-1522.

34. House AA, Eliasziw M, Cattran DC, Churchill DN, Oliver MJ, et al. (2010) Effect of B-vitamin therapy on progression of diabetic nephropathy: a randomized controlled trial. JAMA 303: 1603-1609.

35. Babaei-Jadidi R, Karachalias N, Ahmed N, Battah S, Thornalley PJ (2003) Prevention of incipient diabetic nephropathy by high-dose thiamine and benfotiamine. Diabetes 52: 2110-2120.

36. Rabbani N, Alam SS, Riaz S, Larkin JR, Akhtar MW, et al. (2009) High-dose thiamine therapy for patients with type 2 diabetes and microalbuminuria: a 
Citation: Maclsaac RJ, Ekinci El, Kelly DJ, Jerums G (2012) New Treatments for Diabetic Chronic Kidney Disease. J Nephrol Therapeutic S2. doi:10.4172/2161-0959.S2-006

Page 7 of 7

randomised, double-blind placebo-controlled pilot study. Diabetologia 52: 208212

37. Alkhalaf A, Klooster A, van Oeveren W, Achenbach U, Kleefstra N, et al. (2010) A double-blind, randomized, placebo-controlled clinical trial on benfotiamine treatment in patients with diabetic nephropathy. Diabetes Care 33: 1598-1601.

38. Sharma K, Ix JH, Mathew AV, Cho M, Pflueger A, et al. (2011) Pirfenidone for diabetic nephropathy. J Am Soc Nephrol 22: 1144-1151.

39. Kelly DJ, Zhang Y, Gow R, Gilbert RE (2004) Tranilast attenuates structural and functional aspects of renal injury in the remnant kidney model. J Am Soc Nephrol 15: 2619-2629.

40. Soma J, Sato K, Saito H, Tsuchiya Y (2006) Effect of tranilast in early-stage diabetic nephropathy. Nephrol Dial Transplant 21: 2795-2799.

41. Holmes DR Jr, Savage M, LaBlanche JM, Grip L, Serruys PW, et al. (2002) Results of Prevention of REStenosis with Tranilast and its Outcomes (PRESTO) trial. Circulation 106: 1243-1250.

42. Zammit SC, Cox AJ, Gow RM, Zhang Y, Gilbert RE, et al. (2009) Evaluation and optimization of antifibrotic activity of cinnamoyl anthranilates. Bioorg Med Chem Lett 19: 7003-7006.

43. Thomas MC, Cooper ME (2011) Diabetes: Bardoxolone improves kidney function in type 2 diabetes. Nat Rev Nephrol 7: 552-553.

44. Jiang T, Huang Z, Lin Y, Zhang Z, Fang D, et al. (2010) The protective role of Nrf2 in streptozotocin-induced diabetic nephropathy. Diabetes 59: 850-860.

45. Pergola PE, Raskin P, Toto RD, Meyer CJ, Huff JW, et al. (2011) Bardoxolone methyl and kidney function in CKD with type 2 diabetes. N Engl J Med 365: 327-336.

46. http://clinicaltrials.gov/. (2012) [cited 201230 Jan 2012]

47. Colhoun HM, Betteridge DJ, Durrington PN, Hitman GA, Neil HA, et al. (2009) Effects of atorvastatin on kidney outcomes and cardiovascular disease in patients with diabetes: an analysis from the Collaborative Atorvastatin Diabetes Study (CARDS). Am J Kidney Dis 54: 810-819.

48. Luk AO, Yang X, Ma RC, Ng VW, Yu LW, et al. (2010) Association of statin use and development of renal dysfunction in type 2 diabetes--the Hong Kong Diabetes Registry. Diabetes Res Clin Pract 88: 227-333.

49. de Zeeuw D (2010) Different renal protective effects of atorvastatin and rosuvastatin in diabetic and non-diabetic renal patients with proteinuria. Results of hte PLANET trials. European Renal Association- European Dialsys and Transplant Association Congress; Munich Germany.

50. Shepherd J, Kastelein JJ, Bittner V, Deedwania P, Breazna A, et al. (2008) Intensive lipid lowering with atorvastatin in patients with coronary heart disease and chronic kidney disease: the TNT (Treating to New Targets) study. J Am Coll Cardiol 51: 1448-1454

51. Baigent C, Landray MJ, Reith C, Emberson J, Wheeler DC, et al. (2011) The effects of lowering LDL cholesterol with simvastatin plus ezetimibe in patients with chronic kidney disease (Study of Heart and Renal Protection): a randomised placebo-controlled trial. Lancet 377: 2181-2192.

52. Cheung AK (2009) Is lipid control necessary in hemodialysis patients?. Clin J Am Soc Nephrol 1: S95-S101.

53. Drury PL, Ting R, Zannino D, Ehnholm C, Flack J, et al. (2011) Estimated glomerular filtration rate and albuminuria are independent predictors of cardiovascular events and death in type 2 diabetes mellitus: the Fenofibrate Intervention and Event Lowering in Diabetes (FIELD) study. Diabetologia 54: 32-43.

54. Davis TM, Ting R, Best JD, Donoghoe MW, Drury PL, et al. (2011) Effects of fenofibrate on renal function in patients with type 2 diabetes mellitus: the Fenofibrate Intervention and Event Lowering in Diabetes (FIELD) Study. Diabetologia 54: 280-290.

55. Hermans MP (2011) Non-invited review: prevention of microvascular diabetic complications by fenofibrate: lessons from FIELD and ACCORD. Diab Vasc Dis Res 8: 180-189.
56. Kelly DJ, Zhang Y, Hepper C, Gow RM, Jaworski K, et al. (2003) Protein kinase $\mathrm{C}$ beta inhibition attenuates the progression of experimental diabetic nephropathy in the presence of continued hypertension. Diabetes 52: 512-518.

57. Koya D, Haneda M, Nakagawa H, Isshiki K, Sato H, et al. (2000) Amelioration of accelerated diabetic mesangial expansion by treatment with a PKC beta inhibitor in diabetic $\mathrm{db} / \mathrm{db}$ mice, a rodent model for type 2 diabetes. FASEB $J$ 14: 439-447.

58. Tuttle KR, Bakris GL, Toto RD, McGill JB, Hu K, et al. (2005) The effect of ruboxistaurin on nephropathy in type 2 diabetes. Diabetes Care 28: 2686-2690.

59. Lambers Heerspink HJ, Fowler MJ, Volgi J, Reutens AT, et al. (2007) Rationale for and study design of the sulodexide trials in Type 2 diabetic, hypertensive patients with microalbuminuria or overt nephropathy. Diabet Med 24: 1290 1295.

60. Heerspink HL, Greene T, Lewis JB, Raz I, Rohde RD, et al. (2008) Effects of sulodexide in patients with type 2 diabetes and persistent albuminuria. Nephrol Dial Transplant 23: 1946-1954.

61. Lewis EJ, Lewis JB, Greene T, Hunsicker LG, Berl T, et al. (2011) Sulodexide for kidney protection in type 2 diabetes patients with microalbuminuria: a randomized controlled trial. Am J Kidney Dis 58: 729-736.

62. Packham DK, Wolfe R, Reutens AT, Berl T, Heerspink HL, et al. (2012) Sulodexide Fails to Demonstrate Renoprotection in Overt Type 2 Diabetic Nephropathy. J Am Soc Nephrol 23: 123-130.

63. Noh H, Oh EY, Seo JY, Yu MR, Kim YO, et al. (2009) Histone deacetylase-2 is a key regulator of diabetes- and transforming growth factor-beta1-induced renal injury. Am J Physiol Renal Physiol 297:F 729-F739.

64. Gilbert RE, Huang Q, Thai K, Advani SL, Lee K, et al. (2011) Histone deacetylase inhibition attenuates diabetes-associated kidney growth: potential role for epigenetic modification of the epidermal growth factor receptor. Kidney Int 79: 1312-1321.

65. McCormick BB, Sydor A, Akbari A, Fergusson D, Doucette S, et al. (2008) The effect of pentoxifylline on proteinuria in diabetic kidney disease: a metaanalysis. Am J Kidney Dis 52: 454-463.

66. Navarro-Gonzalez JF, Muros M, Mora-Fernandez C, Herrera H, Meneses B, et al. (2011) Pentoxifylline for renoprotection in diabetic nephropathy: the PREDIAN study. Rationale and basal results. J Diabetes Complications 25: 314-319.

67. Miao Y, Ottenbros SA, Laverman GD, Brenner BM, Cooper ME, et al. (2011) Effect of a reduction in uric acid on renal outcomes during losartan treatment a post hoc analysis of the reduction of endpoints in non-insulin-dependent diabetes mellitus with the Angiotensin II Antagonist Losartan Trial. Hypertension 58: 2-7.

68. Goicoechea M, de Vinuesa SG, Verdalles U, Ruiz-Caro C, Ampuero J, et al. (2010) Effect of allopurinol in chronic kidney disease progression and cardiovascular risk. Clin J Am Soc Nephrol 5: 1388-1393.

69. Gaede P, Lund-Andersen H, Parving HH, Pedersen O (2008) Effect of a multifactorial intervention on mortality in type 2 diabetes. N Engl J Med 358 580-591.

70. Chan JC, So WY, Yeung CY, Ko GT, Lau IT, et al. (2009) Effects of structured versus usual care on renal endpoint in type 2 diabetes: the SURE study: a randomized multicenter translational study. Diabetes Care 32: 977-982. 